\title{
Paroxysmal atrial fibrillation in young cryptogenic ischemic stroke: A 3-week ECG Holter monitoring study
}

\author{
Daniel Sanak ${ }^{\mathrm{a}}$, Martin Hutyra ${ }^{\mathrm{b}}$, Michal Krala ${ }^{\mathrm{a}}$, Andrea Bartkova ${ }^{\mathrm{a}}$, Jana Zapletalova ${ }^{\mathrm{c}}$, Marian Fedorco ${ }^{\mathrm{b}}$, Tomas Veverkaa \\ David Vindis ${ }^{\mathrm{b}}$, Tomas Dornak ${ }^{\mathrm{a}}$, Tomas Skala ${ }^{\mathrm{b}}$, David Skoloudik ${ }^{\mathrm{d}}$, Milos Taborsky ${ }^{\mathrm{b}}$, Petr Kanovsky ${ }^{\mathrm{a}}$
}

Background. Atrial fibrillation is known very frequent cause of ischemic stroke. Undetected paroxysmal atrial fibrillation (PAF) is thus often considered a possible cause of cryptogenic ischemic stroke (CIS). The aim of this prospective study was to detect PAF using ECG Holter monitoring and determinate whether prolongation of the Holter monitoring to 3 weeks would increase the detection rates of PAF in young CIS patients $\leq 50$ years.

Methods. The study set consisted of IS patients $\leq 50$ years enrolled in the HISTORY (Heart and Ischemic STrOke Relationship studY) study (NCT01541163). CIS was defined according to the TOAST criteria including the absence of ultrasonographic or angiographic signs of atherosclerosis, vasculitis or dissection. Admission ECG, serum levels of high sensitive Troponin T (hs TnT) and N-terminal pro-brain natriuretic peptide (NT-proBNP), markers of thrombophilia, transoesophageal echocardiography (TEE) and 24-hour ECG-Holter monitoring were performed in all patients. In case of negative 24-h ECG Holter, an additional 3-weeks monitoring was done.

Results. Of the 105 enrolled patients $\leq 50$ years, 95 (90\%) were identified as cryptogenic (49 males, mean age 39.1 \pm 8.2 years). All CIS patients had normal admission ECG. In total, PAF was detected in 9 (9.5\%, 95\% Cl: 3.5\% - 17.8\%) patients; in two during 24-h ECG Holter and in seven during 3-weeks Holter monitoring. Patients with PAF had more frequently elevated admission hs TnT and NT-proBNP levels ( $P$ - 0.0001).

Conclusions. PAF was detected in $9.5 \%$ of young CIS patients and 3-weeks ECG Holter monitoring increased the detection rate.

Key words: cryptogenic ischemic stroke, paroxysmal atrial fibrillation, ECG Holter monitoring, young stroke

Received: October 29, 2014; Accepted with revision: April 14, 2015; Available online: April 24, 2015

http://dx.doi.org/10.5507/bp.2015.019

${ }^{a}$ Comprehensive Stroke Center, Department of Neurology, University Hospital Olomouc, Czech Republic

${ }^{b}$ Department of Cardiology, University Hospital Olomouc

'Department of Medical Biophysics, Faculty of Medicine and Dentistry, Palacky University Olomouc

${ }^{d}$ Department of Nursing, Faculty of Health Sciences, Palacky University Olomouc

Corresponding author:Daniel Sanak, e-mail:daniel.sanak@centrum.cz

\section{INTRODUCTION}

The cause of ischemic stroke (IS) remains often unclear (cryptogenic) despite an extensive diagnostic pan$\mathrm{el}^{1}$. In young patients, cryptogenic ischemic stroke (CIS) represents more than one third of all ischemic strokes ${ }^{2-4}$. Embolism due to cardiac abnormities, particularly atrial fibrillation (AF), represents a very frequent cause of IS in these patients ${ }^{3-6}$, therefore undetected paroxysmal AF (PAF) is often considered the cause in CIS patients ${ }^{7-8}$. Patients with AF (including transient or paroxysmal forms) have a high risk for recurrent IS and oral anticoagulation is highly effective in secondary prevention ${ }^{9,10}$. Thus, a diagnostic effort should be made to detect PAF in patients with IS. A standard ECG has a limited ability to detect PAF, while a continuous ECG Holter monitoring may increase it $t^{7,8,11,12}$.

The frequency of $\mathrm{AF}$ in young IS patients has not been studied in depth, however undetected AF is considered a cause of IS. A few previous studies have shown the presence of AF in approx. 3-4\% of young IS patients up to 50 years at the time of hospitalization ${ }^{3,413}$. In spite of the greater rate of detected AF using a 24-h ECG Holter monitoring ${ }^{14}$, the presence of $\mathrm{AF}$ in young patients may be underestimated due to insufficient detection of PAF.

The aim of this prospective study was to report detection rates of PAF using an ECG-Holter monitoring in young CIS patients $\leq 50$ years and determine whether prolongation of continuous monitoring (up to 3 weeks) would increase the detection rates of PAF. We assumed our findings might contribute to discussion about an optimal duration of ECG-Holter monitoring for PAF detection in young CIS patients.

\section{MATERIALS AND METHODS}

\section{Patients}

The study set consisted of consecutive acute IS patients $\leq 50$ years, who were enrolled in the prospective single-center observational HISTORY (Heart and Ischemic STrOke Relationship studY) study registered on ClinicalTrials.gov (identifier NCT01541163) between years 2011 and 2014 $\left(\right.$ ref. $\left.{ }^{15}\right)$. In all patients, brain ischemia was confirmed on 
CT or MRI. Patients unable or unwilling to give consent were excluded. The study protocol was in compliance with the current Declaration of Helsinki and study was approved by the Ethics Committee of the hospital.

\section{Data collection and clinical evaluation}

Medical history, baseline characteristics, epidemiologic data, and risk factors were recorded in all patients at admission or during hospitalization. Stroke severity was quantified using the National Institutes of Health Stroke Scale (NIHSS) at admission. All patients underwent following diagnostic work-up: 1) brain CT or MRI on admission and $24 \mathrm{~h}$ later 2 ) serial laboratory samples, 3) admission ECG, 4) ultrasound of cervical and cerebral arteries within first $48 \mathrm{~h}, 4)$ transoesophageal echocardiography (TEE), 5) 24-h ECG Holter monitoring.

The serial laboratory panel used contained the following samples: 1) standard laboratory panel, 2) basic coagulation parameters and standard screening panel of thrombophilia including genetic screening, 3) serum cardiac markers $\leq 12 \mathrm{~h}$ after stroke onset ( $\mathrm{N}$-terminal probrain natriuretic peptide [NT-proBNP], high sensitive Troponin T [hs TnT]), 4) serum levels of glycosylated hemoglobin and lipids $<60 \mathrm{~h}$ after stroke onset. The details and normal values of the specific methods have been published $^{15}$.

CIS was defined according to the Trial of Org 10172 in Acute Stroke Treatment (TOAST) classification ${ }^{16}$ without presence of any known stroke cause including any ultrasonographic or angiographic signs of atherosclerosis, vasculitis or dissection.

All admission ECGs were evaluated by blinded cardiologists (M.H., M.F.). All patients with CIS and negative 24-hour ECG Holter monitoring underwent subsequent 3-week ECG-Holter monitoring. A 24-hour monitoring was performed using a Holter monitor Philips-Zymed DigiTrack plus/DigiTrack XT (Philips, Netherlands) and a 3-weeks monitoring using a Holter monitor MDT Vitaphone Loop 3100 BT (Vitaphone GmbH, Germany). All records from 3-week Loop Holter were processed in an external medical data transfer (MDT) center and evaluated by specially trained and blinded cardiologists. The presence of AF was defined as at least 1 period of $>30$ seconds' duration of an absolute arrhythmia without detectable $P$ waves and without a pattern more consistent with an alternative diagnosis ${ }^{17,18}$.

\section{Statistical analysis}

SPSS software (version 15.0; SPSS Chicago) was used for statistical analysis. Normality of distribution was checked using the Shapiro-Wilk test. All parameters with non-normal distributions are presented a means \pm SD, medians, and interquartile ranges. All tests used an $\alpha$-level of 0.05 for significance.

\section{RESULTS}

In total, 652 consecutive acute IS patients were enrolled in the HISTORY study and 105 (16\%) of them were $\leq 50$ years ( 54 males, $41.2 \pm 8.1$ years $)$. In this patient cohort, two (1.9\%) patients presented with AF on admission. Eight (7.6\%) patients had other known cause of IS (3 patients had a symptomatic arterial dissection, one patient had a symptomatic severe stenosis of the internal carotid artery, one patient had a severe dilatational cardiomyopathy with thrombus in the left ventricle, one patient had an artificial valve replacement with insufficient anticoagulation, two patients had a confirmed severe thrombophilia; one patient had detected resistance of activated protein $\mathrm{C}$ and the other had antiphospholipid syndrome [lupus anticoagulant]). The remaining 95 (88.7\%) patients (49 males, $39.1 \pm 8.2$ years) were identified as cryptogenic and comprised the study set.

In total, PAF was detected in 9 (9.5\%, 95\% CI: 3.5\% $17.8 \%$ ) CIS patients during ECG-Holter monitoring. The demographic and baseline characteristics of these patients are shown in Table 1. There was no significant difference between PAF and CIS patients in these parameters.

A 24-hour ECG-Holter was started after a median of 5.3 days (interquartile range 4.1 - 8.3 days) after admission. 3-week ECG-Holter was performed after a median of 42 days (interquartile range 25 - 96 days) after admission. No interruptions of Holter monitoring and no significant technical difficulties occurred and patients tolerated long-term monitoring. Paroxysmal AF was detected in two patients during 24-h ECG-Holter and in another 7 patients during 3-week monitoring. Mean time from start of 3-week monitoring to the first detection of PAF was $11.5 \pm 3.4$ days.

Patients with detected PAF had elevated admission serum levels of hs TnT and NT-proBNP (Table 2) significantly more frequently than patients without detected AF ( $56 \%$ vs. $2 \%$ and $56 \%$ vs. $3.5 \%, P=0.0001)$. Two (22\%) patients with detected AF had elevated both cardiac markers. There was no difference between groups in terms of a patent foramen ovale (PFO) with an evident right-left shunt on TEE (Table 2).

In all patients with detected PAF, oral anticoagulant therapy was initiated.

\section{DISCUSSION}

The results of our study showed a clear trend towards higher rates of detected PAF with a prolongation of ECGHolter monitoring also in young stroke patients, while this trend was reported previously in elderly population only ${ }^{7,11,19}$. Nevertheless, the rate of detected PAF (9.5\%) in our study was lower than the previously reported rates achieved during 7-day Holter monitoring (12-13\%) $\left(\right.$ ref. $\left.^{7,20}\right)$. This difference may be due the fact that our study population was selected from patients with CIS only and was substantially younger ( $\leq 50$ years). Previously reported age-dependent yields of screening for undetected $\mathrm{AF}$ in stroke patients suggested this explanation ${ }^{20}$. In the recently reported randomized EMBRACE (Cardiac Event Monitor Belt for Recording Atrial Fibrillation after a Cerebral Ischemic Event) study, PAF was detected in $16.1 \%$ of patients over 55 years with cryptogenic stroke using a 30-day ECG-Holter monitoring ${ }^{12}$. 
Table 1. Demographic and baseline stroke characteristics of CIS patients and PAF patients.

\begin{tabular}{lccc}
\hline Characteristics & CIS & PAF & $P$ \\
\hline $\mathrm{N}$ & 86 & 9 & \\
Age (yrs), mean \pm SD & $40.3 \pm 6.2$ & $43.1 \pm 3.2$ & 0.903 \\
Males & $44(51 \%)$ & $5(56 \%)$ & 1.000 \\
Baseline NIHSS & $9(3-18)$ & $8(4-16)$ & 0.986 \\
(Median + interquartile range) & & & \\
Stroke in anterior circulation & $61(71 \%)$ & $6(67 \%)$ & 1.000 \\
History of prior TIA/stroke & $2(2.3 \%)$ & 0 & 1.000 \\
Hypertension & $7(8.1 \%)$ & 0 & 1.000 \\
Diabetes mellitus & $1(1 \%)$ & 0 & 1.000 \\
Hyperlipidemia & $12(14 \%)$ & $1(11 \%)$ & 1.00 \\
Coronary artery disease & 0 & 0 & 1.000 \\
Peripheral artery disease & 0 & 0 & 1.000 \\
Smoking & $21(24 \%)$ & $2(22 \%)$ & 1.000 \\
Alcohol abuse & $2(2 \%)$ & 0 & 1.000 \\
Systolic blood pressure $(\mathrm{mmHg})$ & $135 \pm 7$ & $132 \pm 9$ & 1.000 \\
Diastolic blood pressure $(\mathrm{mmHg})$ & $69 \pm 14$ & $74 \pm 11$ & 0.978 \\
IV thrombolysis & $36(42 \%)$ & $6(67 \%)$ & 0.205 \\
Endovascular treatment & $12(14 \%)$ & $1(11 \%)$ & 1.000 \\
\hline
\end{tabular}

IV = intravenous, NIHSS = National Institutes of Health Stroke Scale, SD = standard deviation, TIA = transient ischemic attack

Table 2. Laboratory parameters and TEE findings of CIS and PAF patients.

\begin{tabular}{lccc}
\hline & CIS patients & PAF patients & $P$ \\
\hline NT-proBNP $>125 \mathrm{ng} / \mathrm{L}$ & $3(3.5 \%)$ & $5(56 \%)$ & 0.0001 \\
Hs TnT $>0.014 \mu \mathrm{g} / \mathrm{L}$ & $2(2 \%)$ & $5(56 \%)$ & 0.0001 \\
Creatinine $>90 \mu \mathrm{mol} / \mathrm{L}$ & $2(2 \%)$ & 0 & 1.000 \\
Baseline serum level of GLU $>5.6 \mathrm{mmol} / \mathrm{L}$ & $46(54 \%)$ & $5(56 \%)$ & 1.000 \\
Glycosylated hemoglobin $>40 \mathrm{mmol} / \mathrm{L}$ & $2(2 \%)$ & 0 & 1.000 \\
Baseline serum level of CH $>5.0 \mathrm{mmol} / \mathrm{L}$ & $25(29 \%)$ & $2(22 \%)$ & 1.000 \\
Left atrial diameter $(\mathrm{mm})($ mean $+\mathrm{SD})$ & $35 \pm 5$ & $36 \pm 8$ & 1.000 \\
Left ventricular ejection fraction $(\%)$ & 55 & 60 & 0.989 \\
PFO with significant right-left shunt & $25(29 \%)$ & $2(22 \%)$ & 1.000 \\
Other defect of atrial septum & $3(3 \%)$ & 0 & 1.000 \\
\hline
\end{tabular}

$\mathrm{CH}=$ cholesterol, $\mathrm{CIS}=$ cryptogenic ischemic stroke, GLU $=$ glucose, hs $\mathrm{TnT}=$ high sensitive Troponin T, NTproBNP $=\mathrm{N}$-terminal pro-brain natriuretic peptide, $\mathrm{PAF}$ paroxysmal atrial fibrillation, $\mathrm{PFO}=$ patent foramen ovale, $\mathrm{SD}=$ standard deviation, TEE = transoesophageal echocardiography

In young IS patients $<50$ years, previous studies showed a frequency of AF up to $5 \%$ (ref., ${ }^{2,30-22}$ ). The use of a 24-h ECG Holter and a prolonged ECG Holter monitoring (up to 7 days) did not increase this low frequency

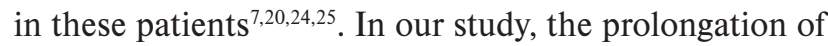
Holter monitoring up to 3 weeks increased substantially the detection rate of PAF with the mean time of $11.5 \pm$ 3.4 days from the start of monitoring to the first detection of PAF.

In our study, the loop recorder was used for the detection of PAF. This type of recorder detects arrhythmias trigged by a patient only. Thus the detection rate may be limited in case of an asymptomatic episode of AF. Continuous telemetric or implantable monitors may provide a more accurate PAF detection. These devices are able to record user-defined, automatic and patient- activated episodes of AF or other arrhythmias ${ }^{26}$. However, in the recently published randomized CRYSTAL AF (Cryptogenic Stroke and Underlying AF) study, the rate of detected PAF did not exceed 10\% during a 6-month period of continuous monitoring ${ }^{27}$.

Paroxysmal AF represents the same risk for a recurrent IS as a permanent form of AF ( ref. $^{28}$ ). Moreover, the frequency of episodes of PAF increases over time and AF may become persistent ${ }^{29}$. The duration of AF is considered necessary for thrombus formation, however the TEE-based studies showed that short intervals of AF may also generate a thrombus ${ }^{30,31}$. Although PAF has been defined as an episode of AF in duration $>30 \mathrm{~s}$ ( ref. $^{17,18}$ ), we assume that shorter periods of $\mathrm{AF}(<30 \mathrm{~s})$ may be also relevant for detection of PAF. We agree with the suggestion that very short AF episodes may be associated 
with longer undetected AF episodes of sufficient duration, which result in thrombus formation and subsequent embolization ${ }^{19}$.

The presence of PFO with evident right-left shunt on TEE was registered only in one patient with detected PAF. Regarding the fact that the thrombus formation due to AF occurs in the left atrium and ventricle primarily ${ }^{31}$, we suggest there is no relevance of PFO in CIS patients with detected PAF. Moreover, the relevance of PFO as a risk factor for IS has been still discussed. Although PFO is more prevalent in IS patients, recently published results from the PC Trial showed no significant benefit of the PFO closure for patients with CIS (ref. ${ }^{32}$ ). Similarly, results from the RESPECT trial were negative in the primary intention-to-treat analysis. However, the additional results from the per-protocol analysis suggested a certain benefit of closure ${ }^{33}$.

The elevation of serum hs TnT and NT-proBNP in our PAF patients may correspond to the reported findings that elevation of hs TnT is associated with AF and that NT-proBNP was found to be a robust predictor of AF, especially in younger patients ${ }^{34,35}$. Thus we suggest the serum elevation of hs TnT and NT-proBNP might help to better identify IS patients with undetected PAF, in whom a diagnostic effort with a sufficient length of ECG-Holter monitoring is needed for detection of PAF.

The study has limitations. A single center study design with a small sample size was used. Nevertheless, the incidence of IS in young patients is generally low and most previously reported studies with young CIS patients $<50$ years had similar sample sizes. The interval from stroke onset to start of 24-h and 3-week ECG Holter was relatively longer. For a 3-week monitoring, the loop recorder with a limited ability to record arrhythmias was used. Thus we cannot exclude the possibility of a higher detection rate if continuous telemetry or implantable recorders were used.

In conclusion, AF (including its transient or paroxysmal forms) represents a high risk for recurrent IS, thus a greater diagnostic effort to detect $\mathrm{AF}$ is required, especially in younger patients with unclear cause of IS. The prolongation of ECG-Holter monitoring up to 3 weeks increased the detection of PAF in these patients.

\section{ACKNOWLEDGMENT}

This study was supported by Grants NT/11046-6/2010 and NT/ NT14288-3/2013 from the Internal Grant Agency of the Ministry of Health of the Czech Republic and by the Institutional Support RVO FNOL 00098892.

Author contributions: DS, MH: study design and manuscript writing; DS, MH, MK, AB, MF, TV, DV, TD, TS, MT: enrollment and data collection; DS, DSk, MH, $\mathrm{AB}, \mathrm{MT}, \mathrm{PK}$ : data analysis and interpretation, manuscript preparation; JZ: statistical analysis.

Conflict of interest statement: The authors state that there are no conflicts of interest regarding the publication of this article.

\section{REFERENCES}

1. Kolominsky-Rabas PL,Weber M, Gefeller O, Neundoerfer B, Heuschmann PU. Epidemiology of ischemic stroke subtypes according to TOAST criteria: incidence, recurrence, and longterm survival in ischemic stroke subtypes: a population-based study. Stroke 2001;32:2735-40.

2. Cerrato $P$, Grasso $M$, Imperiale D, Priano $L$, Baima $C$, Giraudo $M$ Rizzuto A, Azzaro C, Lentini A, Bergamasco B. Stroke in young patients: etiopathogenesis and risk factors in different age classes. Cerebrovasc Dis 2004;18:154-9.

3. Putaala J, Metso AJ, Metso TM, Konkola N, Kraemer Y, Haapaniemi E, Kaste M, Tatlisumak T. Analysis of 1008 consecutive patients aged 15 to 49 with first-ever ischemic stroke: the Helsinki young stroke registry. Stroke 2009;40:1195-203.

4. Putaala J, Haapaniemi E, Metso AJ, Metso TM, Artto V, Kaste M, Tatlisumak T. Recurrent ischemic events in young adults after firstever ischemic stroke. Ann Neurol 2010;68:661-71.

5. Ferro JM, Massaro AR, Mas JL. Aetiological diagnosis of ischaemic stroke in young adults. Lancet Neurol 2010;9:1085-96.

6. Varona JF, Guerra JM, Bermejo F, Molina JA, Gomez de la Camara A. Causes of ischemic stroke in young adults, and evolution of the etiological diagnosis over the long term. Eur Neurol 2007;57:212-8.

7. Stahrenberg R, Weber-Krüger M, Seegers J, Edelmann F, Lahno R, Haase B, Mende M, Wohlfahrt J, Kermer P, Vollmann D, Hasenfuß G, Gröschel K, Wachter R. Enhanced Detection of Paroxysmal Atrial Fibrillation by Early and Prolonged Continuous Holter Monitoring in Patients With Cerebral Ischemia Presenting in Sinus Rhythm. Stroke 2010;41:2884-8.

8. Seet RC, Friedman PA, Rabinstein AA. Prolonged rhythm monitoring for the detection of occult paroxysmal atrial fibrillation in ischemic stroke of unknown cause. Circulation 2011;124:477-86.

9. Hart RG, Pearce LA, Aguilar MI. Adjusted-dose warfarin versus aspirin for preventing stroke in patients with atrial fibrillation. Ann Intern Med 2007;147:590-2.

10. Kirchhof $P$, Curtis $A B$, Skanes AC, Gillis AM, Samuel Wann L, John Camm A. Atrial fibrillation guidelines across the Atlantic: a comparison of the current recommendations of the European Society of Cardiology/European Heart Rhythm Association/European Association of Cardiothoracic Surgeons, the American College of Cardiology Foundation/American Heart Association/Heart Rhythm Society, and the Canadian Cardiovascular Society. Eur Heart J 2013;34:1471-4.

11. Liao J, Khalid Z, Scallan C, Morillo C, O'Donnell M. Noninvasive cardiac monitoring for detecting paroxysmal atrial fibrillation or flutter after acute ischemic stroke: a systematic review. Stroke 2007;38:2935-40.

12. Gladstone DJ, Spring M, Dorian P, Panzov V, Thorpe KE, Math M, Hall J, Vaid H, O'Donnell M, Laupacis A, Cote R, Sharma M, Blakely JA, Shuaib A, Hachinski V, Coutts SB, Sahlas DJ, Teal P, Yip S, Spence JD, Buck B, Verreault S, Casaubon LK, Penn A, Selchen D, Jin A, Howse D, Mehdiratta M, Boyle K, Aviv R, Kapral MK, Mamdani M for the EMBRACE Investigators and Coordinators. Atrial Fibrillation in Patients with Cryptogenic Stroke. N Engl J Med 2014;370:2467-77.

13. Chatzikonstantinou $A$, Wolf ME, Hennerici MG. Ischemic stroke in young adults: classification and risk factors. J Neurol 2012;259:653-9.

14. Prefasi D, Martinez-Sanchez P, Rodrıguez-Sanz A, Fuentes B, Filgueiras-Rama D, Ruiz-Ares G, Sanz-Cuesta BE, Dıez-Tejedor E. Atrial fibrillation in young stroke patients: do we underestimate its prevalence? Eur J Neurol 2013;20:1367-74.

15. Kral M, Skoloudik D, Sanak D, Veverka T, Bartkova A, DornakT, Hutyra M, Vindis D, Ulehlova J , Slavik L, Svabova M, Kubickova V, Herzig R, Kanovsky P. Assessment of relationship between acute ischemic stroke and heart disease - protocol of a prospective observational trial. Biomed Pap Med Fac Univ Palacky Olomouc Czech Repub 2012;156:284-9.

16. Adams HP Jr, Bendixen BH, Kappelle LJ, Biller J, Love BB, Gordon $\mathrm{DL}$, Marsh EE III. Classification of subtype of acute ischemic stroke. Definitions for use in a multicenter clinical trial. TOAST. Trial of Org 10172 in Acute Stroke Treatment. Stroke 1993;24:35-41.

17. Fuster V, Ryden LE, Cannom DS, Crijns HJ, Curtis AB, Ellenbogen KA Halperin JL, Le Heuzey JY, Kay GN, Lowe JE, Olsson SB, Prystowsky EN, Tamargo JL, Wann S, Smith SC Jr, Jacobs AK, Adams CD, Anderson $J \mathrm{~L}$, Antman EM, Hunt SA, Nishimura R, Ornato JP, Page RL, Riegel B, 
Priori SG, Blanc JJ, Budaj A, Camm AJ, Dean V, Deckers JW, Despres C, Dickstein K, Lekakis J, McGregor K, Metra M, Morais J, Osterspey A, Zamorano JL. ACC/AHA/ESC 2006 guidelines for the management of patients with atrial fibrillation: a report of the American College of Cardiology/American Heart Association Task Force on Practice Guidelines and the European Society of Cardiology Committee for Practice Guidelines (writing committee to revise the 2001 guidelines for the management of patients with atrial fibrillation): developed in collaboration with the European Heart Rhythm Association and the Heart Rhythm Society. Circulation 2006;114:257-354.

18. Kirchhof P, Auricchio A, Bax J, Crijns H, Camm J, Diener HC, Goette A Hindricks G, Hohnloser S, Kappenberger L, Kuck KH, Lip GY, Olsson B, Meinertz T, Priori S, Ravens U, Steinbeck G, Svernhage E, Tijssen J, Vincent A, Breithardt G. Outcome parameters for trials in atrial fibrillation: recommendations from a consensus conference organized by the German Atrial Fibrillation Competence Network and the European Heart Rhythm Association. Europace 2007;9:1006-23.

19. Tayal AH, Tian M, Kelly KM, Jones SC, Wright DG, Singh D, Jarouse J, Brillman J, Murali S, Gupta R. Atrial fibrillation detected by mobile cardiac outpatient telemetry in cryptogenic TIA or stroke. Neurology 2008;71:1696-701.

20. Wachter R, Weber-Krüger M, Seegers J, Edelmann F, Wohlfahrt J, Wasser K, Gelbrich G, Hasenfuß G. Age-dependent yield of screening for undetected atrial fibrillation in stroke patients: the Find-AF study. J Neurol 2013;260:2042-45.

21. Gattellari M, Goumas C, Aitken R, Worthington JM. Outcomes for patients with ischaemic stroke and atrial fibrillation: the PRISM study (a Program of Research Informing Stroke Management). Cerebrovasc Dis 2011;32:370-82.

22. Larrue V, Berhoune N, Massabuau P, Calviere L, Raposo N, Viguier A, Nasr N. Etiologic investigation of ischemic stroke in young adults. Neurology 2011; 76: 1983-8.

23. Marini C, De Santis F, Sacco S, Russo T, Olivieri L, Totaro R, Carole A. Contribution of atrial fibrillation to incidence and outcome of ischemic stroke: results from population-based study. Stroke 2005;36:1115-9.

24. Rizos T, Güntner J, Jenetzky E, Marquardt L, Reichardt C, Becker R, Reinhardt R, Hepp T, Kirchhof P, Aleynichenko E, Ringleb P, Hacke W, Veltkamp R. Continuous Stroke Unit Electrocardiographic Monitoring Versus 24-Hour Holter Electrocardiography for Detection of Paroxysmal Atrial Fibrillation After Stroke. Stroke 2012;43:2689-94.

25. Grond M, Jauss M, Hamann G, Stark E, Veltkamp R, Nabavi D, Horn M, Weimar C, Köhrmann M, Wachter R, Rosin L, Kirchhof P. Improved detection of silent atrial fibrillation using 72-hour Holter ECG in pa- tients with ischemic stroke: a prospective multicenter cohort study. Stroke 2013;44:3357-64.

26. Winkler S, Axmann C, Schannor B, Kim S, Leuthold T, Scherf M Downes R, Nettlau H, Koehler F. Diagnostic accuracy of a new detection algorithm for atrial fibrillation in cardiac telemonitoring with portable electrocardiogram devices. J Electrocardiol 2011;44:460-4.

27. Sanna T, Diener HC, Passman RS, Di Lazzaro V, Bernstein RA, Morillo CA, Mollman Rymer M, Thijs V, Rogers T, Beckers F, Lindborg K, and Brachmann J, for the CRYSTAL AF Investigators. Cryptogenic Stroke and Underlying Atrial Fibrillation. N Engl J Med 2014;370:2478-86.

28. Hart RG, Pearce LA, Rothbart RM, McAnulty JH, Asinger RW, Halperin $J$. Stroke with intermittent atrial fibrillation: incidence and predictors during aspirin therapy. Stroke Prevention in Atrial Fibrillation Investigators. J Am Coll Cardiol 2000;35:183-7.

29. Kerr CR, Humphries KH, Talajic M, Klein GJ, Connolly SJ, Green M Boone J, Sheldon R, Dorian P, Newman D. Progression to chronic atrial fibrillation after the initial diagnosis of paroxysmal atrial fibrillation: result from the Canadian Registry of Atrial Fibrillation. Am Heart J 2005;149:489-96.

30. Stoddard MF, Dawkins PR, Prince CR, Ammash NM. Left atrial appendage thrombus is not uncommon in patients with acute atrial fibrillation and a recent embolic event: a transesophageal echocardiographic study. J Am Coll Cardiol 1995;25:452-9.

31. Manning WJ, Silverman DI, Waksmonski CA, Oettgen P, Douglas PS. Prevalence of residual left atrial thrombi among patients with acute thromboembolism and newly recognized atrial fibrillation. Arch Intern Med 1995; 155:2193-8.

32. Meier B, Kalesan B, Mattle HP, Khattab AA, Hildick-Smith D, Dudek D, Andersen G, Ibrahim R, Schuler G, Walton AS, Wahl A, Windecker $S$, Jüni P; PC Trial Investigators. Percutaneous closure of patent foramen ovale in cryptogenic embolism. N Engl J Med 2013;368:108391.

33. Carroll JD, Saver JL, Thaler DE, Smalling RW, Berry S, MacDonald LA, Marks DS, Tirschwell DL; RESPECT Investigators et al. for the RESPECT investigators. Closure of patent foramen ovale versus medical therapy after cryptogenic stroke. N Engl J Med 2013;368:1092-100.

34. Anegawa $T$, Kai $H$, Adachi $H$, Hirai $Y$, Enomoto $M$, Fukami A, Otsuka M, Kajimoto H, Yasuoka S, Iwamoto Y, Aoki Y, Fukuda K, Imaizumi T. High-sensitive troponin $\mathrm{T}$ is associated with atrial fibrillation in a general population. Int J Cardiol 2012;156:98-100.

35. Patton KK, Heckbert SR, Alonso A, Bahrami H, Lima JA, Burke $\mathrm{G}$, Kronmal RA. N-terminal pro-B-type natriuretic peptide as a predictor of incident atrial fibrillation in the Multi-Ethnic Study of Atherosclerosis: the effects of age, sex and ethnicity. Heart 2013;99:1832-6. 